\section{(6) OPEN ACCESS}

\title{
Stress resilience and physical fitness in adolescence and risk of coronary heart disease in middle age
}

\author{
Cecilia Bergh, ${ }^{1}$ Ruzan Udumyan, ${ }^{1}$ Katja Fall, ${ }^{1}$ Henrik Almroth, ${ }^{2}$ Scott Montgomery ${ }^{1,3,4}$
}

- Additional material is published online only. To view please visit the journal online (http://dx.doi.org/10.1136/ heartjnl-2014-306703).

1 Department of Clinical Epidemiology and Biostatistics, Faculty of Medicine and Health, Örebro University, Örebro, Sweden

${ }^{2}$ Department of Cardiology, Faculty of Medicine and Health, Örebro University, Örebro, Sweden

${ }^{3}$ Clinical Epidemiology Unit, Karolinska University Hospital, Karolinska Institutet, Stockholm, Sweden ${ }^{4}$ Department of Epidemiology and Public Health, University College London, London, UK

\section{Correspondence to}

Cecilia Bergh, Department of Clinical Epidemiology and Biostatistics, Örebro University Hospital, Örebro 70185 , Sweden; cecilia.bergh@oru.se

Received 22 August 2014 Revised 25 December 2014 Accepted 26 December 2014 Published Online First 4 March 2015

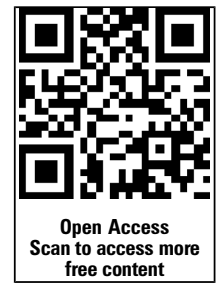

CrossMark

To cite: Bergh C, Udumyan R, Fall $\mathrm{K}$, et al. Heart 2015;101:623-629.

\begin{abstract}
Objective Psychosocial stress is a suggested risk for coronary heart disease (CHD). The relationship of stress resilience in adolescence with subsequent CHD risk is underinvestigated, so our objective was to assess this and investigate the possible mediating role of physical fitness.
\end{abstract}

Methods In this register-based study, 237980 men born between 1952 and 1956 were followed from 1987 to 2010 using information from Swedish registers. Stress resilience was measured at a compulsory military conscription examination using a semistructured interview with a psychologist. Some 10581 diagnoses of $\mathrm{CHD}$ were identified. Cox regression estimated the association of stress resilience with CHD, with adjustment for established cardiovascular risk factors. Results Low-stress resilience was associated with increased CHD risk. The association remained after adjustment for physical fitness and other potential confounding and mediating factors, with adjusted HRs (and $95 \% \mathrm{Cls}$ ) of 1.17 (1.10 to 1.25), with some evidence of mediation by physical fitness. CHD incidence rates per 1000 person-years (and 95\% Cls) for lowstress, medium-stress and high-stress resilience were 2.61 (2.52 to 2.70), 1.97 (1.92 to 2.03) and 1.59 (1.53 to 1.67 ) respectively. Higher physical fitness was inversely associated with CHD risk; however, this was attenuated by low-stress resilience, shown by interaction testing $(p<0.001)$.

Conclusions Low-stress resilience in adolescence was associated with increased risk of CHD in middle age and may diminish the benefit of physical fitness. This represents new evidence of the role of stress resilience in determining risk of CHD and its interrelationship with physical fitness.

\section{INTRODUCTION}

It has been suggested that exposure to psychosocial stress is associated with a variety of adverse health outcomes, including coronary heart disease (CHD), ${ }^{1}{ }^{2}$ although the evidence to date is inconclusive. $^{2-4}$ Some studies even suggest a similar magnitude of risk for stress as other major cardiovascular risk factors. ${ }^{5}$ Psychosocial stress is a potentially feasible risk for cardiovascular disease (CVD) through its influence on the hypothalamic pituitary adrenal (HPA) axis and the sympathetic nervous system, which may alter metabolic and cardiac autonomic control as well as resulting in inflammation. ${ }^{6}$ Moreover, stress may be related to lifestyle factors relevant to CHD risk such as cigarette smoking, alcohol consumption and physical inactivity. ${ }^{7}$
There have been potential methodological concerns in some studies of psychosocial stress and CHD risk, making clear causal inference difficult, including problems of reporting bias due to the use of retrospectively collected information. ${ }^{1}{ }^{5}$ Short duration follow-up is unlikely to capture significant chronic accumulation of risk. It is also possible that stressful exposures in middle age are confounded by other previously accumulated CHD risks. A further issue is that there is between-individual variation in what constitutes stressful exposures or the ability to cope with them and few studies have taken these factors into account.

Little attention has been paid to the consequences of ability to cope with stress, or stress resilience, in the assessment of CHD risk. Low-stress resilience, possibly resulting in a prolonged physiological response to stressful exposures, might be important in determining the risk of CHD due to chronic stress. Animal studies have demonstrated that early-life stress can alter HPA axis function in a way that can persist over the life course as low resilience to stress. ${ }^{8}{ }^{9}$ Recent evidence suggests that factors acting across the life course are important in determining the risk of CVD. ${ }^{10}$ Low-stress resilience, as assessed during a military conscription assessment in adolescence before the accumulation of CHD risk factors in adulthood, has previously been associated with increased stroke risk in middle-aged men, and this association was explained in part by poor physical fitness. ${ }^{11}$ Other studies using Swedish conscription examination data found that better physical fitness in adolescence is associated with a reduced risk of $\mathrm{CHD},{ }^{12}$ as well as with lower depression risk in adulthood. ${ }^{13}$ However, a recent Cochrane review did not strongly support exercise interventions to improve symptoms of depression: ${ }^{14}$ this suggests that stress and stress resilience may influence fitness and exercise. If this is so, we hypothesise that higher-level physical fitness in adolescence may be less protective against $\mathrm{CHD}$ if it is accompanied by lower levels of stress resilience as this might lead to greater attenuation of physical activity, or its benefits, over time.

Our primary objective was to investigate whether stress resilience in adolescence is associated with subsequent CHD in adulthood. A secondary aim was to examine the role of physical fitness from two perspectives. First, we considered it as a mediator to explain a component of the association between stress resilience and CHD risk. Second, we examined whether the association of physical fitness with CHD risk varied by level of stress 
resilience (effect modification), with the hypothesis that higherlevel fitness in adolescence may not be as protective against CHD among those with low-stress resilience. This study used Swedish register data with prospectively collected information for a national cohort of men, with detailed information from childhood and adolescence and a long follow-up into late middle age.

\section{METHODS}

\section{Study population}

The study cohort comprised all male Swedish residents born between 1952 and 1956, who were eligible for military conscription and included in the Swedish Military Conscription Register. At the time, conscription was compulsory for all male citizens of the appropriate age (18 and 19 years) and the conscription examination included extensive medical, psychiatric and physical assessments to establish health, fitness and psychological profiles. Subsequent risk of CHD was assessed from 1987 (when the Swedish National Patient Register ${ }^{11}$ attained full coverage) to 2010. From a total of 284198 men identified, complete data were available for 237980 after exclusions as detailed in the online supplement. The sample available for the main analysis comprised $84 \%$ of the potential target population. Missing data were predominantly due to exclusions owing to chronic illness or disability. Approximately 4\% did not attend the assessments for this reason. Among the remaining men with missing data, 77\% had conditions that made them ineligible for conscription and no further testing was undertaken. Thus, the cohort is somewhat selected for better health at baseline.

\section{Measures \\ Stress resilience, physical fitness and other characteristics in adolescence}

Stress resilience, physical and cognitive function, and disease diagnoses in adolescence were assessed as part of the military conscription examination. All men underwent a psychological examination to assess their potential ability to cope with stress in military service, ${ }^{15}{ }^{16}$ based on the ability to control and channel nervousness, tolerance of stress and disposition to anxiety. The potential conscripts met a psychologist for a semistructured interview that covered areas relevant to general everyday life, including dimensions such as social maturity, leisure interests, psychological energy and emotional stability. ${ }^{17}$ This interview was used to produce a stress resilience score from 1 to 9, which we grouped into low (1-3), medium (4-6) and high (7-9). Higher values indicate greater stress resilience. To ensure consistent evaluation, a central authority supervised the instruction and training of participating psychologists, supported by a written manual. Some details of the test are only available in Swedish, ${ }^{18}$ and not all military information is available to the public. However, it has been used in other studies. ${ }^{11} 1519$

Physical fitness was assessed using a cycle ergometer test. After a normal resting ECG, a maximal test with gradually increasing load until volitional exhaustion was performed. Starting loads varied, depending on physical stature, history of physical activity and medical history. In men with a medical condition not allowing a maximal test, a submaximal test was performed or an estimate was derived for conscripts with current infectious disease or other condition, according to physical stature, history of physical activity and medical history. The resulting value (watts) was transformed into scores with a range from 0 to $9 .^{20}$ Height and weight were used to calculate body mass index (BMI), which was categorised using the WHO criteria. Systolic and diastolic blood pressure was measured after rest in recumbent men using a sphygmomanometer. The cognitive test was a written assessment and comprised four domains: linguistic understanding, spatial recognition, general knowledge and ability to follow mechanical instructions; the results were transformed into a single score with a value ranging from 1 to 9 . From the medical assessment at conscription, we identified diagnoses and used International Classification of Diseases (ICD)-8 codes 393-458 to indicate diagnosis of any CVD at the time of conscription.

Socioeconomic and demographic characteristics

The government organisation Statistics Sweden provided socioeconomic and demographic data including information on vital status and emigration. Childhood social and material circumstances were estimated using data from the Population and Housing Census in 1960. ${ }^{11}$ Household crowding was derived by dividing number of household members by number of habitable rooms.

\section{Ascertainment of CHD events}

CHD diagnoses in the cohort were obtained through the Swedish National Patient Register (inpatients and outpatients) and the Cause of Death Register using ICD codes (see online supplementary information). We identified the dates of first fatal and non-fatal CHD during the period 1969-2010.

\section{Statistical analysis}

Analyses were performed using SPSS V.22, Stata V.13 SE and R V.3.1.2. Cox regression was used to examine the association of stress resilience in adolescence with subsequent risk of CHD between ages 31 and 58 years. Follow-up started from 1 January 1987 and ended on the date of first CHD diagnosis, death, emigration or 1 January 2010, whichever occurred first. Subjects with a diagnosis of CHD before 1987 were excluded $(n=140)$. Non-fatal and fatal CHD were examined together and separately. In the analyses of CHD subtypes, first event for each subtype was used.

Associations were examined using an unadjusted (model 1) and three further adjusted models. In model 2, adjustment was for demographic and socioeconomic factors for the family of origin: birth year, geographical region, parental socioeconomic index and household crowding. Model 3 was additionally adjusted for characteristics in adolescence: cognitive function (continuous), systolic and diastolic blood pressure (continuous) and CVD at conscription (except CHD, as men with this diagnosis in adolescence were excluded). In model 4 , lifestyle factors in adolescence (represented by physical fitness and body mass) were also added to the model: BMI (in four categories) and physical fitness score (continuous). Sensitivity analyses included additional adjustment for psychiatric disease at conscription and another that excluded men who had an estimated fitness test. Mediation analysis ${ }^{21}$ (performed using $\mathrm{R}$ software) was used to assess the mediating role of physical fitness in the association of stress resilience in adolescence with later $\mathrm{CHD}$.

The association of physical fitness with CHD was calculated separately for each stress resilience level (stratification). Effect modification by resilience was examined in the entire population using interaction testing on a multiplicative scale. The proportional hazards assumptions for stress resilience in relation to CHD outcomes were tested graphically, as well as using a test based on Schoenfeld residuals, and no evidence for violation was found. HRs were estimated with $95 \%$ CIs and statistical significance was defined as $\mathrm{p}<0.05$. 


\section{RESULTS}

During the follow-up period of 1987-2010, 10581 men $(4.4 \%)$ received an inpatient or outpatient diagnosis of $\mathrm{CHD}$, or CHD was recorded as the underlying cause of death. All covariates were statistically significantly associated with resilience. Men with low resilience tended to have lower levels of physical fitness and cognitive function scores, higher blood pressure, underweight, overweight or obesity, a diagnosis of CVD at conscription, parents from lower socioeconomic circumstances and greater household crowding in childhood (table 1).

All characteristics investigated showed statistically significant associations with CHD (all CHD, fatal CHD, acute myocardial infarction (MI), fatal MI and angina pectoris). The associations with all CHD for stress resilience, physical fitness and BMI are reported in table 2 . The results indicate a graded association for stress resilience with CHD with a higher risk for individuals with low-stress resilience. The incidence rates also showed a graded association with highest (absolute) risk in lowest stress resilience group. When adjusted for demographic and socioeconomic factors in childhood, the HRs attenuated somewhat but remained statistically significant. Additional adjustment for health and developmental characteristics in adolescence notably attenuated the association. Further adjustment for physical fitness and BMI had a further notable impact on the HRs but statistical significance remained. Sensitivity analyses (see online supplementary tables S2-S4) did not markedly change the associations. Mediation analysis indicated that approximately 19\% $(13.8-24.5 \%)$ of the association between low-stress resilience and CHD was mediated by physical fitness, and for the association between medium resilience and $\mathrm{CHD}$ the proportion mediated by physical fitness was about 28\% (18.8-41.5\%).
Table 3 presents the outcomes for CHD subgroups, acute MI $(n=5820)$, fatal MI $(n=766)$, angina pectoris $(n=6171)$ and fatal CHD $(n=1280)$. All showed a significant and graded association with stress resilience in unadjusted and adjusted models, with higher magnitude associations for fatal disease.

The inverse graded association of physical fitness scores (0-9) with CHD outcomes was less pronounced in the low-resilience group when examined in stratified analysis. Statistically significant effect modification was confirmed by interaction testing (table 4). Men with low resilience were not at as much of a reduced CHD risk even if they had a higher level of physical fitness. When stratified analysis was additionally adjusted for BMI, there is only a small alteration in estimates as HRs were slightly lower.

\section{DISCUSSION}

In this general population-based cohort study, we demonstrated that low-stress resilience measured in adolescence was associated with an increased risk of CHD in middle-aged men. The results were somewhat affected by childhood socioeconomic circumstances, as well as health and developmental characteristics in adolescence. The association was further attenuated, but not eliminated, by adjustment for physical fitness and BMI in adolescence, likely to signal future lifestyle characteristics. Our results showed an independent association of stress resilience with CHD. Some of the association was mediated through lower physical fitness among those with lower stress resilience. As expected, higher physical fitness in adolescence was associated with lower risk of CHD, but it is notable that this effect was attenuated or eliminated in the low-stress resilience group,

Table 1 Population ( $n=237$ 980) characteristics by stress resilience levels

\begin{tabular}{|c|c|c|c|c|}
\hline & $\begin{array}{l}\text { High-stress (7-9) } \\
\text { resilience } \\
\mathrm{n}=56308\end{array}$ & $\begin{array}{l}\text { Moderate-stress (4-6) } \\
\text { resilience } \\
n=129806\end{array}$ & $\begin{array}{l}\text { Low-stress (1-3) } \\
\text { resilience } \\
\mathrm{n}=51866\end{array}$ & p Value \\
\hline Physical fitness* & $\begin{array}{l}\mathrm{N}(\%) \\
7.2(1.7)\end{array}$ & $\begin{array}{l}\mathrm{N}(\%) \\
6.2(1.7)\end{array}$ & $\begin{array}{l}\mathrm{N}(\%) \\
5.5(1.7)\end{array}$ & $<0.001$ \\
\hline Body mass index $\left(\mathrm{kg} / \mathrm{m}^{2}\right), \mathrm{N}(\%)$ & & & & $<0.001$ \\
\hline Underweight $(<18.499)$ & $3723(6.6)$ & $15409(11.9)$ & $8539(16.5)$ & \\
\hline Normal weight (18.5-24.999) & $48639(86.4)$ & $104749(80.7)$ & $38916(75.0)$ & \\
\hline Overweight (25.0-29.999) & $3619(6.4)$ & $8334(6.4)$ & $3661(7.1)$ & \\
\hline Obese $(\geq 30.0)$ & $327(0.6)$ & $1314(1.0)$ & $750(1.4)$ & \\
\hline Cognitive function* & $6.1(1.7)$ & $5.2(1.8)$ & $4.2(2.0)$ & $<0.001$ \\
\hline Diastolic blood pressure* $(\mathrm{mm} \mathrm{Hg})$ & $71.3(8.5)$ & $71.7(8.6)$ & $72.1(8.8)$ & $<0.001$ \\
\hline Systolic blood pressure* $(\mathrm{mm} \mathrm{Hg})$ & $127.6(11.1)$ & $127.7(11.1)$ & $127.6(11.2)$ & 0.026 \\
\hline CVD diagnosis & & & & 0.010 \\
\hline Yes & $1484(2.6)$ & $3637(2.8)$ & $1523(2.9)$ & \\
\hline No & $54824(97.4)$ & $126169(97.2)$ & $50343(97.1)$ & \\
\hline Parental SEI 1960, N (\%) & & & & $<0.001$ \\
\hline Manual workers & $19111(33.9)$ & $55137(42.5)$ & $24636(47.5)$ & \\
\hline Agricultural workers & $1449(2.6)$ & $5323(4.1)$ & $2461(4.7)$ & \\
\hline Farm owners/managers & $5287(9.4)$ & $14138(10.9)$ & $4327(8.3)$ & \\
\hline Office workers & $20431(36.3)$ & $34147(26.3)$ & $11431(22.0)$ & \\
\hline Business owners/managers & $6958(12.4)$ & $13830(10.7)$ & $4734(9.2)$ & \\
\hline Others/unknown & $3072(5.5)$ & $7231(5.6)$ & $4277(8.2)$ & \\
\hline \multicolumn{5}{|l|}{ Household crowding, 1960, N (\%) } \\
\hline$\leq 2$ people/room & $47497(84.4)$ & $101516(78.2)$ & $36866(71.1)$ & $<0.001$ \\
\hline$>2$ people/room & $8811(15.6)$ & $28290(21.8)$ & $15000(28.9)$ & \\
\hline
\end{tabular}


Table 2 Risk of coronary heart disease (all CHD) associated with stress resilience, physical fitness and body mass

\begin{tabular}{|c|c|c|c|c|c|}
\hline & \multirow[b]{2}{*}{$\begin{array}{l}\text { Event rates } / 1000 \\
\text { person-years }(95 \% \mathrm{Cl})\end{array}$} & \multirow{2}{*}{$\begin{array}{l}\text { Unadjusted } \\
\text { Model } 1 \\
\text { HR }(95 \% \mathrm{Cl})\end{array}$} & \multicolumn{3}{|l|}{ Adjusted } \\
\hline & & & $\begin{array}{l}\text { Model } 2 \\
\text { HR (95\% Cl) }\end{array}$ & $\begin{array}{l}\text { Model } 3 \\
\text { HR }(95 \% \mathrm{Cl})\end{array}$ & $\begin{array}{l}\text { Model } 4 \\
\text { HR }(95 \% \mathrm{Cl})\end{array}$ \\
\hline \multicolumn{6}{|l|}{ Main exposure } \\
\hline \multicolumn{6}{|l|}{ Stress resilience } \\
\hline 1. High (7-9) & 1.59 (1.52 to 1.67$)$ & Reference & Reference & Reference & Reference \\
\hline 2. Moderate (4-6) & 1.97 (1.92 to 2.03$)$ & 1.24 (1.18 to 1.30$)$ & 1.18 (1.12 to 1.25$)$ & 1.09 (1.02 to 1.15$)$ & $1.04(0.98$ to 1.09$)$ \\
\hline 3. Low (1-3) & 2.61 (2.52 to 2.70$)$ & 1.65 (1.56 to 1.75$)$ & 1.54 (1.45 to 1.63$)$ & 1.28 (1.21 to 1.36$)$ & $1.17(1.10$ to 1.25$)$ \\
\hline \multicolumn{6}{|l|}{ Mediators } \\
\hline Physical fitness (per unit change, 0-9) & & 0.93 (0.92 to 0.94$)$ & & & $0.93(0.92$ to 0.94$)$ \\
\hline \multicolumn{6}{|l|}{ Body mass index $\left(\mathrm{kg} / \mathrm{m}^{2}\right)$} \\
\hline Underweight $(<18.49)$ & 1.70 (1.60 to 1.80$)$ & 0.88 (0.83 to 0.94$)$ & & & $0.78(0.73$ to 0.83$)$ \\
\hline Normal weight (18.5-24.99) & $1.92(1.80$ to 1.96$)$ & Reference & & & Reference \\
\hline Overweight (25.0-29.99) & 3.36 (3.17 to 3.36$)$ & 1.76 (1.66 to 1.88$)$ & & & $1.63(1.53$ to 1.74$)$ \\
\hline Obese $(\geq 30.0)$ & $5.22(4.63$ to 5.89$)$ & 2.79 (2.47 to 3.15$)$ & & & 2.23 (1.97 to 2.52$)$ \\
\hline
\end{tabular}

consistent with our hypothesis that stress resilience modifies the association of fitness with CHD risk.

The results of the present study are consistent with our recent findings suggesting a role for stress and stress resilience in the aetiology of stroke in working-age men. ${ }^{11}$ Similarly, poorer adaptation to social adversity-possibly signalling lower stress resilience-has been linked with an increased risk of stroke ${ }^{22}$ and mortality. ${ }^{23}$ These results are consistent with the literature suggesting a role for stress in the development of CHD where several mechanisms have been proposed. ${ }^{3}$ Measurement of stress in recent studies has been heterogeneous, but few studies have focused on stress susceptibility or resilience as examined here. Thus, we hypothesise that possible sources of low-stress resilience include poorer control of the stress response due to exposure to psychosocial stress in early-life ${ }^{8}$ or inherited characteristics.

Adverse socioeconomic conditions in childhood could influence risk of later CHD, so we adjusted for such factors with

Table 3 Stress resilience and coronary heart disease (CHD) divided by diagnoses and fatality

\begin{tabular}{|c|c|c|c|c|c|}
\hline & \multirow[b]{2}{*}{$\begin{array}{l}\text { Event rates/ } 1000 \\
\text { person-years }(95 \% \mathrm{Cl})\end{array}$} & \multirow{2}{*}{$\begin{array}{l}\text { Unadjusted } \\
\text { Model } 1 \\
\text { HR }(95 \% \mathrm{Cl})\end{array}$} & \multicolumn{3}{|l|}{ Adjusted } \\
\hline & & & $\begin{array}{l}\text { Model } 2 \\
\text { HR }(95 \% \mathrm{Cl})\end{array}$ & $\begin{array}{l}\text { Model } 3 \\
\text { HR }(95 \% \mathrm{Cl})\end{array}$ & $\begin{array}{l}\text { Model } 4 \\
\text { HR }(95 \% \mathrm{Cl})\end{array}$ \\
\hline \multicolumn{6}{|c|}{ Acute myocardial infarction $(n=5820)$} \\
\hline \multicolumn{6}{|l|}{ Stress resilience } \\
\hline High 7-9 & $0.86(0.81$ to 0.92$)$ & Reference & Reference & Reference & Reference \\
\hline Moderate 4-6 & 1.08 (1.04 to 1.12$)$ & 1.24 (1.16 to 1.33$)$ & 1.19 (1.11 to 1.27$)$ & 1.10 (1.03 to 1.18$)$ & $1.03(0.96$ to 1.11$)$ \\
\hline Low 1-3 & 1.44 (1.38 to 1.51$)$ & 1.68 (1.56 to 1.81$)$ & 1.56 (1.45 to 1.69$)$ & 1.32 (1.22 to 2.43$)$ & $1.18(1.08$ to 1.28$)$ \\
\hline \multicolumn{6}{|c|}{ Fatal myocardial infarction $(n=766)$} \\
\hline \multicolumn{6}{|c|}{ Stress resilience } \\
\hline High 7-9 & 0.09 (0.08 to 0.11$)$ & Reference & Reference & Reference & Reference \\
\hline Moderate 4-6 & $0.14(0.13$ to 0.15$)$ & $1.48(1.20$ to 1.81$)$ & 1.39 (1.13 to 1.71$)$ & 1.25 (1.02 to 1.55$)$ & $1.17(0.95$ to 1.45$)$ \\
\hline Low 1-3 & $0.22(0.19$ to 0.25$)$ & 2.32 (1.86 to 2.89$)$ & 2.13 (1.71 to 2.66$)$ & 1.68 (1.33 to 2.12 ) & 1.49 (1.16 to 1.90$)$ \\
\hline \multicolumn{6}{|c|}{ Angina pectoris $(\mathrm{n}=6171)$} \\
\hline \multicolumn{6}{|c|}{ Stress resilience } \\
\hline High 7-9 & $0.92(0.86$ to 0.97$)$ & Reference & Reference & Reference & Reference \\
\hline Moderate 4-6 & 1.15 (1.11 to 1.19$)$ & $1.26(1.22$ to 1.35$)$ & $1.20(1.12$ to 1.28$)$ & 1.10 (1.03 to 1.18$)$ & 1.05 (0.97 to 1.12$)$ \\
\hline Low 1-3 & $1.52(1.45$ to 1.59$)$ & 1.67 (1.56 to 1.80$)$ & 1.55 (1.44 to 1.67$)$ & 1.29 (1.19 to 1.40$)$ & 1.18 (1.08 to 1.28$)$ \\
\hline \multicolumn{6}{|l|}{ Fatal CHD $(n=1280)$} \\
\hline \multicolumn{6}{|l|}{ Stress resilience } \\
\hline High 7-9 & $0.17(0.15$ to 0.19$)$ & Reference & Reference & Reference & Reference \\
\hline Moderate 4-6 & $0.23(0.21$ to 0.24$)$ & 1.35 (1.15 to 1.58$)$ & 1.28 (1.09 to 1.50$)$ & 1.15 (0.98 to 1.35$)$ & $1.10(0.93$ to 1.29$)$ \\
\hline Low 1-3 & 0.38 (0.34 to 0.42$)$ & 2.29 (1.94 to 2.71$)$ & 2.11 (1.79 to 2.50$)$ & 1.66 (1.39 to 1.98$)$ & 1.52 (1.27 to 1.83$)$ \\
\hline
\end{tabular}


Table 4 Physical fitness (per unit change; 0-9) and coronary heart disease (CHD) subgroups stratified by stress resilience

\begin{tabular}{|c|c|c|c|c|c|}
\hline & Sample size & $\begin{array}{l}\text { All CHD } \\
\text { HR }(95 \% \mathrm{Cl})\end{array}$ & $\begin{array}{l}\text { Fatal CHD } \\
\text { HR }(95 \% \mathrm{Cl})\end{array}$ & $\begin{array}{l}\text { MI } \\
\text { HR }(95 \% \mathrm{Cl})\end{array}$ & $\begin{array}{l}\text { Angina pectoris } \\
\text { HR }(95 \% \mathrm{Cl})\end{array}$ \\
\hline Highest resilience group & 56308 & & & & \\
\hline \multirow[t]{2}{*}{ Physical fitness } & & $0.92(0.90$ to 0.95$) \neq$ & $0.92(0.85$ to 1.00$) \ddagger$ & 0.91 (0.88 to 0.94$) \ddagger$ & 0.91 (0.88 to 0.94$) \ddagger$ \\
\hline & & 0.91 (0.88 to 0.93$) \S$ & 0.91 (0.83 to 0.98$) \S$ & 0.89 (0.86 to 0.93$) \S$ & $0.89(0.86$ to 0.92$) \S$ \\
\hline Moderate resilience group & 129806 & & & & \\
\hline \multirow[t]{2}{*}{ Physical fitness } & & 0.95 (0.94 to 0.97$) \mp, \uparrow$ & 0.95 (0.91 to 1.00$) \ddagger, \neq \ddagger$ & $0.94(0.92$ to 0.96$) \ddagger$, $\neq$ & $0.94(0.93$ to 0.96$) \neq, \uparrow$ \\
\hline & & 0.93 (0.91 to 0.94$) \S, \neq \neq$ & 0.92 (0.88 to 0.97$) \S, \neq \ddagger$ & 0.91 (0.89to 0.93$) \S_{\text {, } \neq \ddagger}$ & $0.92(0.90$ to 0.94$) \S, \neq \neq$ \\
\hline Lowest resilience group & 51866 & & & & \\
\hline \multirow[t]{2}{*}{ Physical fitness } & & $0.99(0.96$ to 1.01$) \ddagger$, & $1.02(0.97$ to 1.08$) \ddagger, \emptyset$ & $0.97(0.95$ to 1.00$) \ddagger$, & $1.00(0.97$ to 1.03$) \neq, 9$ \\
\hline & & 0.95 (0.93 to 0.97$) \S, 9$ & $1.00(0.94$ to 1.06$) \S_{,} \neq \ddagger$ & 0.94 (0.91 to 0.97$) \S, 9$ & $0.97(0.94$ to 1.00$) \S, 9$ \\
\hline
\end{tabular}

little impact on the association of stress resilience with CHD. Adjustment for developmental characteristics in adolescence, including cognitive function and blood pressure, had some influence on the association. Markers of early-life exposures to stress have been linked with poorer cognitive development ${ }^{24}$ and higher blood pressure, ${ }^{25}$ so adjusting for these factors may represent consequences of earlier stressful exposures that result in poorer stress resilience. Therefore, adjusting for these factors may have produced conservative estimates of association, arguably an overadjustment. Markers of stressful exposures in early life are also linked with unhealthy weight gain, ${ }^{26}$ which may influence physical exercise or be a consequence of low-exercise levels. ${ }^{27}$ BMI and physical fitness could be a consequence of lower stress resilience, at least in part. Our results suggest that a proportion of the association of stress and stress resilience with CVD risk is due to lifestyle risk factors, signalled by the physical fitness score and BMI, as approximately $19 \%$ of the association with low resilience and $28 \%$ of the association with medium resilience were mediated by physical fitness. This is consistent with recent findings from a British cohort study with older participants, which found that the association of psychological distress with CVD is largely explained by behavioural or lifestyle factors; ${ }^{28}$ however, that study did not distinguish between different types of CVD diagnoses. Our study suggests that such processes might have a long natural history, beginning in childhood or adolescence. Our results are consistent among the different CHD subtypes, although the magnitude of association was somewhat greater for fatal events, consistent with our findings for stroke, ${ }^{11}$ suggesting that stress resilience is associated with both risk and severity of CVD. We can only speculate on possible mechanisms, but these might include factors such as social isolation $^{29}$ as this has been associated with a raised risk of cardiovascular mortality, particularly in men with 'type A behaviour'. ${ }^{30}$ Thus, low-stress resilience may have characteristics similar to such a personality trait or may be a consequence of a trait, like 'type A personality'.

It is notable that interaction testing revealed that among those with low-stress resilience, the beneficial association with higher physical fitness was eliminated. Physical fitness may fail to offer as great a protective effect in the face of other exposures associated with low-stress resilience. Alternatively, those with low-stress resilience who were fit in adolescence may have failed to maintain such high-fitness levels into later adulthood. We suggest that these explanations are not mutually exclusive. If physical fitness diminishes with age more rapidly in those with poorer stress resilience, then the mediating role of physical fitness may be of greater magnitude than suggested by our analysis as fitness was measured only in adolescence.

Overweight, obesity and poorer physical fitness in adolescence are likely to signal an accumulation of behavioural health risks that continue through adulthood. Other lifestyle factors in the years between conscription and CHD diagnosis, such as smoking, alcohol and diet, are also likely to be relevant mediating factors. We believe that stress resilience is implicated in the aetiology of CHD and also that a component of the association is mediated by lifestyle factors. We believe that stress resilience can influence cardiovascular outcomes through different nonmutually exclusive pathways: men with low-stress resilience will be more affected by stressful events in their everyday life and more likely to suffer chronic stress with potential physiological consequences; and stress resilience can also influence behavioural factors such as exercise, smoking and diet.

Strengths of the study include the use of prospectively recorded data from several linked registers with high completeness and the long-term follow-up subsequent to the measure of resilience. The study population is largely representative of the male general population as only a small proportion of Swedish men were exempted from enlistment examinations. Extensive physical and psychological assessments were conducted in adolescence; therefore, adjustment could be made for powerful objectively measured cardiovascular risk factors such as physical fitness, BMI and cognitive function. The duration between conscription examination and start of follow-up reduced the possibility of reverse causation, meaning it is unlikely that early CVD symptoms were driving the stress resilience measure. We also had the possibility to identify pre-existing CVD and adjust for blood pressure. The validity of CHD diagnoses recorded in the Swedish National Inpatient Register is high. ${ }^{31}$

A potential limitation is that the study included only men, as was military conscription at this time. Therefore, it is possible that the results would not be identical among women. We cannot be certain about the stability of the measure of stress resilience over time as it was measured only once and do not know precisely how this characteristic may interact with stressful exposures. As stressful exposures were not examined, it is possible that the magnitude of associations with CVD risk for stress 
resilience is conservative. The temporal relationship between stress resilience and physical fitness in adolescence cannot be established, but we hypothesise that poor stress resilience is likely to have its origins in earlier life and that resilience may potentially have an adverse influence on physical fitness. Unfortunately, we have no data on smoking, which could have added further to our understanding of lifestyle risks. However, a study of Swedish male conscripts in 1969 with information on smoking (not available in our study) found that 59\% overall were smokers and among those with low emotional control, which equates with low-stress resilience, the proportion was $66 \%$. ${ }^{32}$ Therefore, it is possible that smoking is a consequence of low-stress resilience and acts as a mediating factor for a component of the association with CHD risk. However, we cannot exclude the possibility that if smoking is implicated in this association, then pre-existing smoking may in turn influence stress resilience. Similarly, smoking may be one of the factors that reduce the protective effect of better physical fitness among men with lower stress resilience.

\section{CONCLUSIONS}

Low-stress resilience in adolescence was associated with increased risk of CHD in middle age and may diminish the benefit of physical fitness. These results provide new evidence of the role of stress resilience in determining risk of CHD and its interrelationship with physical fitness.

\section{Key messages}

\section{What is already known on this subject?}

Exposure to psychosocial stress has been identified as a risk factor for coronary heart disease (CHD), but the role of stress resilience in adolescence, relevant to chronic stress, is less well understood. High physical fitness in adolescence is associated with a reduced risk of CHD in later life.

\section{What might this study add?}

Low-stress resilience in adolescence was associated with increased risk of CHD. Our results further suggest that physical fitness varies by stress resilience level and that the protective effect of fitness in adolescence is reduced or eliminated in those with low-stress resilience. This provides new evidence of the role of stress and stress resilience in adolescence in determining risk of CHD many years later.

\section{How might this impact on clinical practice?} Effective CHD prevention might focus on promoting both physical fitness and tackling stress.

Contributors All authors fulfil the authorship requirements and have approved of the final version of the manuscript. Study hypothesis and design was developed by $C B, S M$ and KF. Data preparation was conducted by $C B, H A$ and RU, and analyses by $C B$ and RU. CB wrote the first draft of the manuscript to which all authors made significant and subsequent intellectual contributions.

Funding This study received support from the UK Economic and Social Research Council (ESRC) as grants to the International Centre for Life Course Studies (grants RES-596-28-0001 and ES/J019119/1) and was also funded by grants from Stiftelsen Olle Engqvist Byggmästare, Folksam and Strategic funding from Örebro University.

Competing interests None.

Ethics approval The Regional Ethics Committee in Uppsala, Sweden (Dnr 2009/306).

Provenance and peer review Not commissioned; externally peer reviewed.
Data sharing statement We do not have permission to share these data, but they are available to academic researchers with ethical permission who apply to the relevant Swedish authorities.

Open Access This is an Open Access article distributed in accordance with the Creative Commons Attribution Non Commercial (CC BY-NC 4.0) license, which permits others to distribute, remix, adapt, build upon this work non-commercially, and license their derivative works on different terms, provided the original work is properly cited and the use is non-commercial. See: http://creativecommons.org/ licenses/by-nc/4.0/

\section{REFERENCES}

1 Rosengren A, Hawken S, Ounpuu S, et al. Association of psychosocial risk factors with risk of acute myocardial infarction in 11119 cases and 13648 controls from 52 countries (the INTERHEART study): case-control study. Lancet 2004:364:953-62.

2 Dimsdale JE. Psychological stress and cardiovascular disease. J Am Coll Cardiol 2008:51:1237-46.

3 Steptoe A, Kivimaki M. Stress and cardiovascular disease. Nat Rev Cardiol 2012;9:360-70.

4 Macleod J, Davey Smith G, Heslop P, et al. Psychological stress and cardiovascula disease: empirical demonstration of bias in a prospective observational study of Scottish men. BMJ 2002:324:1247-51.

5 Yusuf S, Hawken S, Ounpuu S, et al. Effect of potentially modifiable risk factors associated with myocardial infarction in 52 countries (the INTERHEART study): case-control study. Lancet 2004;364:937-52

6 Brotman DJ, Golden SH, Wittstein IS. The cardiovascular toll of stress. Lancet 2007;370:1089-100.

7 Siegrist J, Rodel A. Work stress and health risk behavior. Scand J Work Environ Health 2006;32:473-81.

8 Liu D, Diorio J, Tannenbaum B, et al. Maternal care, hippocampal glucocorticoid receptors, and hypothalamic-pituitary-adrenal responses to stress. Science 1997;277:1659-62.

9 Sapolsky RM. The importance of a well-groomed child. Science 1997;277:1620-1.

10 Li S, Chen W, Srinivasan SR, et al. Childhood cardiovascular risk factors and carotid vascular changes in adulthood: the Bogalusa Heart Study. JAMA 2003:290:2271-6.

11 Bergh C, Udumyan R, Fall K, et al. Stress resilience in male adolescents and subsequent stroke risk: cohort study. I Neurol Neurosurg Psychiatry 2014:85:1331-6

12 Hogstrom G, Nordstrom A, Nordstrom P. High aerobic fitness in late adolescence is associated with a reduced risk of myocardial infarction later in life: a nationwide cohort study in men. Eur Heart J 2014;35:3133-40.

13 Aberg MA, Waern M, Nyberg J, et al. Cardiovascular fitness in males at age 18 and risk of serious depression in adulthood: Swedish prospective population-based study. Br J Psychiatry 2012:201:352-9.

14 Rimer J, Dwan K, Lawlor DA, et al. Exercise for depression. Cochrane Database Syst Rev 2012;7:Cd004366.

15 Nilsson PM, Nyberg P, Ostergren PO. Increased susceptibility to stress at a psychological assessment of stress tolerance is associated with impaired fetal growth. Int J Epidemiol 2001;30:75-80.

16 Falkstedt D, Sorjonen K, Hemmingsson T, et al. Psychosocial functioning and intelligence both partly explain socioeconomic inequalities in premature death A population-based male cohort study. PloS ONE 2013;8:e82031.

17 Otto U. Male youths. A sociopsychiatric study of a total annual population of Swedish adolescent boys. Acta Psychiatr Scand Supp/ 1976;264:1-312.

18 Lothigius J. Verksamhetsinstruktion för Psykologer VIP95 (Psychological Test Manual used by the Swedish National Service Administration VIP95). Pliktverket: Karlstad, 1995.

19 Montgomery S, Udumyan R, Magnuson A, et al. Mortality following unemployment during an economic downturn: Swedish register-based cohort study. BMJ Open 2013:3:e003031

20 Mattsson $\mathrm{P}$, Lonnstedt I, Nygren I, et al. Physical fitness, but not muscle strength, is a risk factor for death in amyotrophic lateral sclerosis at an early age. J Neurol Neurosurg Psychiatry 2012;83:390-4.

21 Tingely D, Yamamoto $T$, Hirose $\mathrm{K}$, et al. Mediation: $\mathrm{R}$ package for causal mediation analysis. J Stat Software 2014;59:1-38.

22 Surtees PG, Wainwright NW, Luben RL, et al. Adaptation to social adversity is associated with stroke incidence: evidence from the EPIC-Norfolk prospective cohor study. Stroke 2007:38:1447-53.

23 Surtees PG, Wainwright NW, Khaw KT. Resilience, misfortune, and mortality: evidence that sense of coherence is a marker of social stress adaptive capacity. J Psychosom Res 2006;61:221-7.

24 Bergman K, Sarkar P, Glover V, et al. Maternal prenatal cortisol and infant cognitive development: moderation by infant-mother attachment. Biol Psychiatry 2010;67:1026-32. 
25 Montgomery SM, Berney LR, Blane D. Prepubertal stature and blood pressure in early old age. Arch Dis Child 2000;82:358-63.

26 Stenhammar C, Olsson G, Bahmanyar S, et al. Family stress and BMI in young children. Acta Paediatr 2010;99:1205-12.

27 Osika W, Montgomery SM. Physical control and coordination in childhood and adult obesity: Longitudinal Birth Cohort Study. BMJ 2008;337:a699.

28 Hamer M, Molloy GJ, Stamatakis E. Psychological distress as a risk factor for cardiovascular events: pathophysiological and behavioral mechanisms. J Am Coll Cardiol 2008;52:2156-62.
29 Barth J, Schneider S, von Kanel R. Lack of social support in the etiology and the prognosis of coronary heart disease: a systematic review and meta-analysis. Psychosom Med 2010;72:229-38.

30 Orth-Gomer K, Unden AL. Type A behavior, social support, and coronary risk: interaction and significance for mortality in cardiac patients. Psychosom Med 1990;52:59-72.

31 Ludvigsson JF, Andersson E, Ekbom A, et al. External review and validation of the Swedish national inpatient register. BMC Public Health 2011;11:450.

32 Hemmingsson $T$, Kriebel $D$, Tynelius $P$, et al. Adolescent mental health predicts quitting smoking in adulthood: a longitudinal analysis. Eur J Public Health 2008;18:66-70. 